\title{
VIANINHA: ÍNTIMO E PESSOAL
}

Claudia Braga

FUNREI

\begin{abstract}
RESUMO
Este artigo constitui-se em breve reflexão a propósito da posição de Oduvaldo Viana Filho no panorama da produção teatral brasileira das décadas de 1960-1970.
\end{abstract}

\section{PALAVRAS - CHAVE}

Vianinha, teatro brasileiro

\begin{abstract}
Os que falam de revolução e de luta de classe sem se referir explicitamente à vida cotidiana, sem compreender o que há de subversivo no amor e positivo na recusa às proibições, têm na boca um cadáver.
\end{abstract}

Comitê dos Enragés, cartaz na Sorbonne, 1968

INTRODUÇĀO

Nosso país vivenciou diversas crises sociais a partir da instauração de governos de exceção, sobretudo militares. Na proclamação da República, os primeiros governos militares, sobretudo o de Floriano Peixoto, o Marechal de Ferro, promoveram séria perseguição aos intelectuais (por sinal, republicanos), o que, por um lado, resultou em evasão de alguns deles para o interior do país e por outro, levou o movimento teatral a um certo cuidado no trato das questões mais polêmicas, por puro instinto de autopreservação.

Durante a vigência do Estado Novo, nossos autores viram-se novamente às voltas com um estado totalitário cujas preocupações com a ideologia transmitida nos palcos nacionais obrigava a realização de produções distanciadas de assuntos mais seriamente ligados a questões políticas, estimulando mesmo uma certa alienação da cena através de numerosas encenações de comédias musicais ligeiras, sobretudo de autores estrangeiros.

Outro período de exceção na política, o momento histórico da vigência da ditadura militar no Brasil içada ao poder em 1964 é, ao mesmo tempo, um período de intensa movimentaçāo cultural em todo o mundo ocidental, cujos ecos, em nosso país, haviam levado ao início de um processo de reavaliação do posicionamento social do artista frente às novas dimensões da economia e do Estado capitalista.

As diferenciadas tentativas de expressão teatral de que se tem notícia procuravam traduzir as diversas correntes de pensamento vivenciadas pela população intelectual do país. Uma análise crítica das obras dramatúrgicas encenadas e/ou escritas nessa época de nossa história (1968/1984) poderia apoiar-se, portanto, nos mais variados 
enfoques, como por exemplo a militância política de esquerda, a resistêrıcia intelectual à repressão, ou mesmo as diferenças da posição feminina em meio às transformações sociais.

O período era de impasses: a propósito de nossa visão do país em confronto com o que dele se esperava; de nossa perplexidade perante as cada vez mais rápidas transformações mundiais cujos ecos nos chegavam; das perturbadoras mudanças comportamentais que surgiam e se impunham e, finalmente, de impasses, conflitos e soluçōes dentro da própria dramaturgia, numa busca incessante da mais adequada linguagem, da mais clara imagem, numa busca, enfim, de respostas à questão diante da qual detiveram-se críticos e dramaturgos ao longo de toda a existência do país: a da sobrevivência, ou da própria existência de um teatro brasileiro.

Até a chamada "revolução de 1964", os autores engajados numa luta pela transformação social via revolução socialista, na realidade, não se aperceberam que o movimento que incentivavam não só provocava imensa resistência por parte da burguesia, como também não contava com o apoio do próprio proletariado, o qual pretendiam, de certa forma, representar. Por não prever o radicalismo da reação ao movimento, iniciada em 1964 e cujo golpe de misericórdia dá-se com a promulgação do Ato Institucional no 5 , a esquerda brasileira divide-se, a partir de entāo, apresentando posiçōes quase individuais de resistência.

\section{A QUESTÃO DA CONSCIÉNCIA}

Observada em sua totalidade, a produçāo dramatúrgica levada à cena nas décadas de 60 e 70 desenha um interessante retrato social daquele momento histórico. Os textos produzidos e encenados no período buscaram expressar, de diversas maneiras, as tensōes e transformações da época e permitem uma boa compreensão de nosso passado recente. As formas encontradas, todavia, é que diferenciaram os contraditórios pontos de vista de nossos autores frente às questões que lhes foram impostas.

Inúmeros intelectuais brasileiros, profissionais de teatro, traduziram sua angústia diante das questões sociais e políticas que se apresentavam, através de dramas densos, de nítida posição contestatória; os exemplos dessa "dramaturgia de resistência" também seriam inúmeros: pode-se observar este posicionamento político em peças como Papa Higuirte (1968) e Rasga Coração (1974), de Oduvaldo Viana Filho; Prova de Fogo (1968), de Consuelo de Castro; Campeões do Mundo (1979), de Dias Gomes, ou nas obras de autores como Augusto Boal, Gianfrancesco Guarnieri e Maria Adelaide Amaral, entre outros.

As incursões à nossa "história oficial" e conseqüente contestação a alguns fatos do passado histórico foi outra maneira encontrada por nossos autores de impor questionamentos a propósito das verdades dadas como absolutas naquele momento. Vargas (1968), de Dias Gomes; As Confrarias (1969), de Jorge Andrade; Calabar (1972), de Chico Buarque e Rui Guerra e Frei Caneca (1972), de Carlos Queiroz Telles, são obras representativas desse viés.

A dramaturgia nacional em cartaz no período, entretanto, não se resumia àquela cuja tradução imediata, e sem anteparos, era a da resistência ao regime ou da posiçāo política de seus autores. Alguns dramaturgos optaram pela tradução alegórica das 
transformaçōes sociais vividas no momento; outros, pela negação daquela mesma militância na trilha apontada pela contracultura; e outros, ainda, pelo tradicional caminho da crítica social através da comédia de costumes, viés sempre prolífico da dramaturgia nacional.

Oduvaldo Viana Filho, reconhecidamente um dos autores mais representativos do período, invocando a herança dramatúrgica de Martins Pena e Oduvaldo Viana, está entre aqueles que se utilizaram de nossa tradição cômica como meio de crítica social.

A posição assumida por Oduvaldo Viana Filho suscitará ainda maiores divergências entre a esquerda brasileira. Nossos autores mais radicais viam na opção de Vianinha pela comédia de costumes uma situação de covardia e alienação, além de acusarem-no de "entreguismo" ao capital (entre outras produções, Viana Filho era un dos autores de A Grande Família, da Rede Globo de Televisão). Não é este o ponto de vista aqui defendido.

A comédia de costumes tem sido, tradicionalmente, no Brasil, o grande viés da crítica social. Dela se utilizaram nosso primeiro autor teatral, Martins Pena (1815-1848), e diversos outros observadores de nossa sociedade, como Joaquim Manuel de Macedo (1820-1882), França Júnior (1838-1890), Machado de Assis (1839-1908) e Artur Azevedo (1853-1908), que aí encontraram a maneira mais suave e ao mesmo tempo mais objetiva de exercerem sobre a sociedade nacional a mais severa das críticas: a exposição de suas piores mazelas ao ridículo, sua descrição através da mais fina ironia.

Ao optar pela tradução de nossas tensões via comédia de costumes Vianinha estava, portanto, longe de se alienar das frementes questões em pauta. Evitando o confronto direto com uma censura discricionária e ignorante, ao contrário, o autor (como homem de teatro que era) perpetuava nossa mais antiga tradição teatral: o enfrentamento através do riso.

\section{VIANINHA, UMA SUBVERSÄO INTIMA}

$\mathrm{Na}$ trajetória percorrida por Vianinha podem ser observadas tentativas de discussāo de diversas questōes de seu tempo. Até 1968 o autor esteve mais absorvido com o que se poderia chamar de "didatismo político" via dramaturgia, através do qual acreditava poder levar conscientizaçāo sócio-política ao proletariado. A partir do exacerbamento das perseguições políticas, advindas com o decreto Ato Institucional número 5, Vianinha passa a temer pela sobrevivência do próprio fazer teatral.

A decretação do AI-5 leva os dramaturgos, Vianinha em particular, a se defrontarem com duas questões fundamentais: por um lado, a viabilização de formas de expressão que driblassem a violenta censura imposta a partir de então; por outro, a necessidade de manutenção das atividades teatrais em geral, cujas manifestações viram-se indiscriminadamente cerceadas neste momento.

Enquanto a reaçāo de alguns profissionais de teatro é a de confrontamento direto com o "sistema", como por exemplo a de José Celso que, à frente do Oficina, defende um teatro "de choque" baseado nas teorias de Antonin Artaud, Vianinha opta pela observação e descrição do "desatarraxamento" do homem perante os - e dentro dos — novos meios de comunicação. Contrário às propostas do teatro de agressão, 
conforme afirma, por exemplo, no artigo "O meu corpo a corpo", 1 Vianinha vai em busca de uma dramaturgia que expresse sua perplexidade e, sobretudo, suas dificuldades ante os acontecimentos políticos, cujo rumo surpreendera toda a esquerda brasileira.

Único entre os profissionais do período a trazer desde o berço ambas as heranças: a da política (sua família era militante ativa do Partido Comunista) e a do teatro (o dramaturgo e encenador Oduvaldo Viana foi figura consideradíssima no meio teatral, em seu tempo, pela qualidade de seus textos e encenações), Vianinha optará por abandonar o viés óbvio da descrição político-partidária dos fatos e, utilizando-se destas heranças, centrará o foco de suas atenções nas relaçōes familiares - tema básico das comédias de costumes tradicionais - e, mais ainda, nas relaçōes do homem com o novo panorama social, o consumo e os meios de comunicação de massa.

Ele próprio envolvido com o trabalho em televisão (opção encontrada por diversos autores da época como, por exemplo, Dias Gomes, para fugir às perseguições políticas), Vianinha mergulhará, em seus próximos trabalhos teatrais, nos mecanismos de produção da TV e da publicidade. A longa noite de Cristal (escrita em 1969), Corpo a corpo (escrita em 1970) e Allegro desbım (1972) tratam destes temas e demonstram, em sua trajetória, o percurso do próprio autor e seu posicionamento a propósito das lutas pessoais contra o "sistema". Uma leitura conjunta destas três obras específicas é quase uma demonstração das possíveis reações individuais aos mecanismos de comunicação, acompanhadas de suas inevitáveis conseqüências.

A longa noite de Cristal descreve a trajetória de um jornalista de primeira linha de uma emissora de TV (Cristal) quc, ao insistir na divulgação de uma notícia que contraria os interesses dos patrocinadores, dá origem a uma série de acontecimentos que vão ressaltar sua insegurança pessoal e desembocarão em seu afastamento final para uma rádio onde, de madrugada, lê informações astrológicas. Num primeiro embate individual, portanto, o sistema expurga o indivíduo.

Em Corpo a corpo o processo apresentado na Longa noite... é invertido: o sistema absorve o sujeito individual. O personagem principal deste drama é Vivacqua, um publicitário cuja lucidez permite a observação crítica dos absurdos contidos no marketing.

No desenrolar do monólogo, o protagonista expõe opiniōes do autor sobre os meios de comunicação e, sobretudo, sobre a finalidade última do marketing, que é "fazer propaganda pras pessoas serem o que não podem ser (...) o que não têm jeito de ser e ficarem se roendo de inveja". Num texto que também poderia se chamar "A longa noite de Vivacqua" (por passar-se no intervalo único de uma noite), Vianinha observa com certo horror o surgimento de um consumismo desenfreado que se instala naquele momento, incentivado por uma publicidade perversa e irresponsável.

No decorrer da noite durante a qual se desenvolve a trama, a personagem decide abandonar seu altíssimo salário e uma profissão que abomina, em nome de seus ideais. De madrugada, entretanto, um telefonema internacional de seu patrão vem informarlhe de um convite para trabalhar numa agência de publicidade americana. Ainda que tendo perfeita consciência de sua posição e de que a "propaganda é isso, uma

\footnotetext{
IVIANA. O meu corpo a corpo, p. 68-75.
} 
corrida desesperada de todo mundo para vender cenários e humilhação... pra não tomar conhecimento do povo, jogar luxo nos olhos dele...", Vivacqua não hesita, todavia, em abandonar todos os seus projetos de mudança ao "estalar de dedos" do sistema, c mergulhará, absorvido por este, no universo a mericano do marketing, símbolo, para esta geração, dos piores defeitos do capitalismo selvagem.

Entre as peças teatrais de Vianinha a empregarem a observaçāo social via comédia de costumes, deter-nos-emos entretanto, aqui, em Allegro desbum (título modificado pela censura oficial para Allegro desbundaccio), cujo subtítulo é Se Martins Pena fosse vivo, pela admissão formal de absorção da herança cômica nacional.

O Allegro desbum demonstra uma terceira reação individual, acompanhada de outra vitória do "sistema" sobre o indivíduo. Buja, o protagonista do Allegro, assim como Vivacqua, é um publicitário aclamado, cujas criações são inevitavelmente sucesso de venda para os produtos. Em crise com os mesmos processos da propaganda já citados no Corpo a corpo, e reafirmados no Allegro..., Buja, ao contrário de seu antecessor, abandona salário e cargo de criação em uma famosa empresa de publicidade, na tentativa de ignorar ou sobrepujar o execrado "sistema".

Sua atitude de negar a sociedade de consumo não prevê, todavia, o abandono do modelo de consumo desta sociedade. Para sustentar-se pretende, a princípio, vender a idéia de um livro, assim como vendia idéias de marketing. Ao perceber que este projeto malograra, o protagonista vai aceitando pequenas criações free-lance, para a mesma empresa publicitária na qual trabalhara. Finalmente, a moça pela qual se apaixona no decorrer da trama, inteiramente imersa na sociedade que o personagem tenta negar, decide casar-se com o publicitário que ocupa o cargo que fora de Buja (outro publicitário!).

Através de Buja, Vianinha demonstra a inutilidade dos gestos individuais, sobretudo quando se continua a fazer pequenas concessões. Buja procura negar, procura ignorar, como não consegue nem uma coisa nem outra, resta-lhe a melancólica atitude de colocar o traseiro na janela do apartamento como último e deprimente gesto de reação.

O caminho percorrido pelos personagens centrais das três peças em questão é, em última análise, o mesmo: o embate pessoal contra a engrenagem das comunicações que naquele momento se estabelecia e demonstrava seu imenso poder de absorver e iludir. A partir de seus personagens, Vianinha prova, claramente, a inutilidade das reações individuais a esta engrenagem sem o respaldo de uma ideologia consistente, ou através da pura e simples negação a ela.

Por outro lado, para Viana Filho apresenta-se como fundamental a existência de alguma reação coletiva capaz de impedir a absorção da criação pelo sistema produtivo.

Segundo Maria Sílvia Betti,

Mais do que tudo, preocupa-o a idéia de ruptura da vislumbrada integridade, a perspectiva da cisão da consciência do criador, cooptado pelos mecanismos de promoção que se estabelecem com a nova ordem vigente.

\footnotetext{
$\overline{2 \text { VIANA. Corpo a corpo }}$.
} 
Este aspecto, acima de todos, será recorrente a ponto de tornar-se a sua marca como dramaturgo, repercutindo sob a forma de una verdadeira galeria de protagonistas agonicamente cindidos. Diante da tentativa patética de resgate da unidade, torna-se mais flagrante o fato de esta encontrar-se em risco e em desacordo com os valores que se impōem pelos mecanismos da ordem estabelecida. ${ }^{3}$

Poder-se-ia mesmo supor que, ao usar como exemplo o "desajustamento" de seus protagonistas, o autor vai demonstrando sua própria e difícil decisão pessoal de, ao contrário de seus contemporâneos que se lançavam, como estes protagonistas, num embate cego e inútil contra a nova ordem social, optar por uma tentativa de transformação da sociedade feita a partir dela própria, através da análise crítica e cômica via comédia de costumes, uma possível e viável oposição ao sistema, dentro da tradição teatral existente nesse mesmo sistema.

\section{INSERÇĀo OU CONTRACULTURA?}

Um exemplo da opção de Vianinha pela observação social a partir da discussão de todos os movimentos inerentes à sociedade de seu tempo é o aparecimento, em suas obras, do fenômeno da contracultura, tema que, embora aparentemente contrário às suas crenças pessoais, o dramaturgo reconhecerá como opção comportamental de sua geração e abordará em diversos textos como os já citados Corpo a corpo e Allegro Desbum ou, posteriormente, em Rasga Coração (1974).

Em mais uma dissensão ante as posiçōes apregoadas pela esquerda contra o escapismo associado ao movimento, Vianinha ignorou a postura crítica radical diante do fenômeno e reconheceu a força subsumida na opção de "paz e amor" preconizada pela contracultura. $O$ assunto aparece, em seus textos, com a atenção devida a uma profunda manifestação de desprezo pelos processos econômicos e políticos até então utilizados e, ainda que questionável em termos de atitude, a negação de inserção social preconizada pelo movimento é descrita como mais uma opção de crítica ao "sistema" social vigente.

Cabe aqui uma breve explicaçāo sobre o termo contracultura que, possivelmente admite diversas definições. Considerando que propomos uma visão mais ampla do fenômeno, o qual acreditamos poder detectar em textos de períodos diversos, assinalamos a explicação de Carlos Alberto Pereira, segundo a qual

O termo contracultura (...) pode também se referir a alguma coisa mais geral, mais abstrata, um certo modo de contestação, de enfrentamento diante da ordem vigente, de caráter profundamente radical e bastante estranho às formas mais tradicionais de oposição a esta mesma ordem dominante. Un tipo de crítica anárquica - esta parece ser a palavra-chave - que, de certa maneira, "rompe com as regras do jogo" em termos de modo de fazer oposição a uma de terminada situação. Aquela postura ou posição de crítica radical $\mathrm{cm}$ face da cultura convencional (...). Una contracultura, entendida assim, reaparece de tempos em tempos, em diferentes épocas e situaçōes, e costuma ter um papel fortemente revigorador da crítica social. ${ }^{4}$

\footnotetext{
${ }^{3}$ BetT. Oduvaldo Viana Filho, p. 161.

${ }^{4}$ Pereira. O que é contracultura, p.20-22.
} 
A obra sobre a qual nos debruçamos neste pequeno estudo ilustra a assunção de Viana Filho pela discussão do assunto. Por outro lado, ainda que Vianinha credite a Martins Pena a ascendência de seu Allegro, o texto permite a constatação de diversos pontos em comum com a tradição cômica brasileira em geral, inclusive com aquelas comédias representadas pela execrada geração Trianon, ${ }^{5}$ da qual fizera parte Oduvaldo Viana, seu pai.

Poderíamos afirmar, portanto, que o Allegro desbum de Oduvaldo Viana Filho, ao contrário de uma possível alienação ante as posições radicais tomadas por boa parte da classe teatral de seu tempo, é uma opção consciente de crítica, através do possível questionamento das regras do jogo expresso pelo movimento da contracultura, em voga naquele momento. Além disso, pelo fato de utilizar-se da tradição teatral da comédia de costumes para expor e descrever as repercussões imediatas de suas observaçōes, seguindo os passos de seu pai e citando a herança de Pena, ou seja, abandonando o "didatismo teatral" e optando pela análise acurada de questóes mais existenciais, inerentes à classe média, Viana leva sua platéia a uma reflexão muito maior a propósito dos "abismos" existentes naquele tipo de comportamento do que jamais conseguira com o tipo de dramaturgia "engajada" preconizada pela esquerda, e envereda pela observaçāo de diversos tipos de comportamento "negados" pelo tradicionalismo esquerdista.

Na introdução de seu estudo sobre as convenções teatrais na obra de Vianinha, a professora Leslie Damasceno aborda a questão da inserção cultural do teatro na sociedade. Diz ela:

(...) em tempos de relativa coesão social (...) a função comunicativa do teatro parece evidente a todos, sem distinção de classes ou divisōes sociais.

Em tempos assim o teatro tem atuado como uma celebração coletiva e uma reafirmação dos valores culturais compartilhados pela sociedade; sua especificidade tem residido em seu apreciado valor como evento comunitário vivo, vívido e necessário. Em outras palavras, o teatro é experimentado como uma forma específica de comunicação artística coletiva que irá contribuir para o desenvolvimento in telectual e/ou moral de seu público e de seus praticantes, bem como para o entretenimento comunitário. Existe um sentido de organicidade socialmente sancionada entre o artista e o público, uma vez que ambos compartilham o ato participativo da mediação cultural que o teatro pode prover. ${ }^{6}$

Continuando seu comentário, a professora ressalta que, à medida que os interesses dos diferentes setores sociais sejam antagônicos, essa "comunhão" tende a desaparecer ou a mostrar-se enquanto ruptura no interior da obra dramatúrgica. Ao apreciar a trajctória autoral de Oduvaldo Viana Filho, no entanto, mesmo considerando suas conhecidas e proclamadas posiçōes políticas, diametralmente opostas às do regime político em vigor, tem-se a impressão de que, na realidade, é exatamente esta tentativa de "celebraçāo coletiva", de organicidade, o que o impele à mudança de estratégia na concepção de suas obras.

Vianinha criou-se em meio a um ambiente não apenas politizado (seu pai era membro ativo do $\mathrm{PCB}$ ) mas também mergulhado na vivência do teatro, e mais, do teatro

\footnotetext{
${ }^{5}$ Nome genérico dado aos profissionais de teatro em atividade nas décadas de 20 e 30 , devido ao Teatro Trianon, mais representativo teatro da época, onde se apresentavam os profissionais de maior sucesso.

${ }^{6}$ Damasceno. Espaço cultural e convençōes teatrais na obra de Oduvaldo Viana Filho, p.11.
} 
de sucesso. Seu pai, o dramaturgo e encenador Oduvaldo Viana, atuante no movimento teatral das décadas de 20 e 30 , era um nome respeitado que, associado a qualquer produção durante sua vida profissional, era sinônimo de boa qualidade de texto e encenação, assim como de êxito junto a público e crítica. Para Vianinha, portanto, a comédia não estava associada à alienação, muito pelo contrário: os trabalhos teatrais de seu pai, embora associados aos grandes nomes da comédia, nunca deixaram de apresentar preocupaçōes sociais ou de criticar os modelos comportamentais de seu tempo.

Apenas para ilustrar, poderíamos citar, por exemplo, a sátira Amor (1934), de Oduvaldo Viana (pai), na qual o autor questiona diversos "dogmas" da sociedade em que vivia, como a indissolubilidade do casamento (em 1934!), a manutenção das aparências ao custo da infelicidade, a inflexibilidade de pensamento, enfim, atitudes que, mesmo tomadas isoladamente, tornariam o ser humano infeliz e a sociedade mais hipócrita. O desfecho desta "sátira" não poderia ser mais moderno: decepcionado com os rumos dados pela sociedade para sua mais nobre criação, o sentimento do amor, Deus dá à humanidade uma nova chance de vivenciar o sentimento, na esperança de que os homens descobrissem que o Amor não poderia ser enquadrado na hipocrisia das regras. O último quadro mostra todos os personagens usando uma mesma máscara e, como numa dança de robôs, repetindo exatamente os mesmos e equivocados gestos.

Sem impor à sua época uma dramaturgia que fosse contra o gosto daquele público, dentro dos moldes utilizados nos alegres anos 30, a visāo de Viana objetiva uma crítica bastante incisiva às regras de comportamento, cujo fim não fosse o de levar o homem a uma vida melhor, e analisa, também, as obrigaçōes sociais baseadas apenas em convençōes supérfluas e limitadoras. Amor, assim como Allegro Desbundaccio, mostra o homem diante de situações sociais que lhe são adversas, contra as quais não alcança salvaguarda; seus textos não são, entretanto, manifestos sociais escritos para confrontar seu público. Por usarem assuntos pessoais para tratar de questões inerentes à sociedade como um todo, atingem com muito mais profundidade o objetivo de denunciar o absurdo das regras de comportamento dessa sociedade.

Apesar dos quase trinta anos que separam o texto de Viana, pai, do Allegro Desbum de Vianinha, observa-se, em ambos, o total conhecimento da eficácia contida na crítica social sugerida dentro de uma comédia cuja leitura mais imediata era a do puro entretenimento. Se na década de 30 ainda não se nota a preocupação de questionamento do establishment como um todo, que se verificará no período aqui analisado, já lá está, no entanto, a certeza de que os alicerces estabelecidos levam a um conjunto que estaria longe de ser o grupo social ideal. Ao referirem-se à vida cotidiana, à subversão contida no amor, na recusa às proibiçōes, os Viana estão lidando com a vida, com os valores mais íntimos do ser humano individual e, aí sim, sendo extremamente políticos, sendo críticos muito mais contundentes do sistema social.

Apreciando, por outro lado, o alcance das obras, pode-se observar que, cnquanto um texto obviamente politizado ou didático era dirigido e assistido por um público específico, reduzido, a comédia atingia uma vasta platéia. Voltando à professora Leslie, em citação de Raymond Williams: "Um público é sempre a herança mais decisiva em qualquer arte. É a maneira pela qual as pessoas aprenderam a ver e a responder que cria a primeira condição essencial ao drama." Viana Filho, homem de esquerda mas,

${ }_{7}^{7}$ Damasceno. Espaço cultural e convençōes teacrais na obra de Oduvaldo Viana Filho, p.21. 
sobretudo, homem de teatro, pretendia, e conseguiu, com sua guinada de estratégia, alcançar uma platéia cuja tradição teatral mais antiga, vide a referência do autor a Martins Pena, era a do riso provocado pela crítica de costumes.

Nesse sentido, pai e filho foram contestadores da ordem de modo geral. Oduvaldo Viana, questionando um código moral falso e apoiado em valores irrelevantes, distanciados dos verdadeiros desejos do coração humano. Vianinha, denunciando um código econômico-social amparado nos mesmos valores e que, em última análise, acabava por distanciar, da mesma forma, o homem de seu semelhante e de si mesmo.

Ao preterir a preconização abstrata da luta de classes, optando pela análise comportamental de seres humanos, envolvidos com seus problemas existenciais íntimos, Vianinha não apenas aproxima-se do ponto de vista de seu pai, enquanto dramaturgo, como também aproxima-se de si mesmo e de suas próprias questões íntimas, pessoais. Pelo que se conhece de sua vida pessoal, podemos depreender que a dramaturgia de Viana Filho torna-se cada vez mais auto-referente, voltada para a análise de temas que interessam e atemorizam o próprio autor enquanto ser humano: as relações amorosas, as relações do homem com o processo de produção de cultura, a manutenção de posições e ideais diante das circunstâncias político-sociais. Dialeticamente, é exatamente ao voltar-se para si que o autor traduz de forma mais absoluta o outro, é exatamente ao abordar questōes particulares que ele se torna mais subversivo e alcança de forma abrangente a sua platéia. Ao colocar em cena os dilemas que o absorviam enquanto ser social e político, Oduvaldo Viana Filho acaba, na verdade, expondo as dificuldades de toda a sua classe perante a "nova ordem", acaba denunciando a profunda perplexidade de toda a sua geração. 


\section{RÉ S U M É}

Cet article est un petit commentaire sur quelques oeuvres dramatiques de Oduvaldo Viana Filho au milieu de la production théâtral brèsilienne dans les années 1960-1970.

\section{MOTS - CLÉS}

Vianinha, thêâtre brèsilien

\section{REFERÊNCIAS BIBLIOGRÁFICAS}

Betti, Maria Sílvia. Oduvaldo Viana Filho. São Paulo: EDUSP/FAPESP, 1997.

DAMASCENO, Leslie Hawkins. Espaço cultural e convenções teatrais na obra de Oduvaldo Viana Filho. Campinas: Editora UNICAMP, 1994.

Hollanda, Heloísa B. de, Gonçalves, Marcos A. Cultura e participação nos anos 60. São Paulo: Brasiliense, 1986.

Pereira, Carlos Alberto M. O que é contracultura. São Paulo: Brasiliense, 1985.

VIAnA, Oduvaldo. Allegro desbundaccio. Comédia. 36 fl. mimeo. UNI-RIO

VIANA, Oduvaldo. Corpo a corpo. Revista da SBAT, n. 387, Rio de Janeiro, 1972.

VianA, Oduvaldo. A longa noite de Cristal. UNI-RIO. (mimeo) 